\title{
From Creative Coding to Digital Humans:
}

\author{
Proceduralism as a Catalyst for Storytelling
}

\author{
Raqi Syed \\ Te Herenga Waka | Victoria \\ University of Wellington \\ raqi.syed@vuw.ac.nz \\ Ripley Shi \\ Weta Digital \\ 10huangyan@gmail.com
}

\author{
Areito Echevarria \\ Te Herenga Waka | Victoria \\ University of Wellington \\ areito.echevarria@vuw.ac.nz \\ Brock Trewavas \\ Weta Digital \\ brocktrewavas@gmail.com
}

\author{
Lucy Jaegers \\ Weta Digital \\ lucyjaegers@gmail.com
}

\author{
Phil Matich \\ Te Herenga Waka | Victoria \\ University of Wellington \\ philipmatich@gmail.com
}

\author{
Junqi Zhang \\ Te Herenga Waka | Victoria \\ University of Wellington \\ kikikunsang@gmail.com
}

\author{
Jared Lee \\ Weta Digital \\ xjared.leex@gmail.com
}

\begin{abstract}
Visual effects is a multi-disciplinary medium-how can we support the next generation of artists to engage deeply with animation, compositing, effects, and lighting in order to produce emotionally and visually compelling narrative work? How do we bridge the gulf between specialties that require an entire career to master? These are the key challenges we face in teaching the Master of Design Technology (MDT), a one-year graduate level program.
\end{abstract}

\section{CCS CONCEPTS}

- Applied Computing: Education; • Applied Computing: Arts and Humanities; - Computing Methodologies: Computer Graphics;

\section{KEYWORDS}

Design, Visual Effects, Creative Coding, Lighting

\section{ACM Reference Format:}

Raqi Syed, Areito Echevarria, Lucy Jaegers, Ripley Shi, Brock Trewavas, Phil Matich, Junqi Zhang, and Jared Lee. 2021. From Creative Coding to Digital Humans:: Proceduralism as a Catalyst for Storytelling. In Special Interest Group on Computer Graphics and Interactive Techniques Conference Educator's Forum (SIGGRAPH '21 Educator's Forum), August 09-13, 2021, Virtual Event, USA. ACM, New York, NY, USA, 2 pages. https://doi.org/10. $1145 / 3450549.3464410$

\section{INTRODUCTION}

We have learned that when students center themselves in a story by understanding code as emotion and the digital human as an

Permission to make digital or hard copies of part or all of this work for personal or classroom use is granted without fee provided that copies are not made or distributed for profit or commercial advantage and that copies bear this notice and the full citation on the first page. Copyrights for third-party components of this work must be honored For all other uses, contact the owner/author(s).

SIGGRAPH '21 Educator's Forum, August 09-13, 2021, Virtual Event, USA

(c) 2021 Copyright held by the owner/author(s)

ACM ISBN 978-1-4503-8363-9/21/08.

https://doi.org/10.1145/3450549.3464410 autobiographical tool, VFX becomes an art medium for telling visually powerful stories. Technical artists are increasingly required to conceptualize creatively and execute technically. In this talk we explore how proceduralism provides both a conceptual and formal framework for learning VFX. We focus on two courses: Creative Coding and Lighting \& Rendering.

In our Creative Coding course students use Houdini to encode their own design aesthetic into procedural systems. This allows them to create story elements that can be varied, customized, and art directed at scale. In our Lighting \& Rendering course students procedurally design avatars using Reallusion's digital human software. We create cinematic tableaus for these characters in Houdini Solaris. We then push these same characters to Unreal Engine, allowing us to measurably understand the affordances of both real-time and offline rendering techniques. At each stage in these courses students learn to work non-destructively, allowing them to prioritize story and make rapid progress across multiple VFX disciplines.

\section{SETTING UP PROCEDURAL THINKING THROUGH CREATIVE CODING}

Creative Coding for Digital Content is part of the core curriculum of MDT and sets up students to pair their explorations in technical art with foundational questions like, who are you and how can you express yourself algorithmically? The course uses concepts of generative design to enable students to procedurally build hard surface assets, terrain, foliage, environments, and animated forms using Houdini VEX. Each exercise in the course investigates a specific design element such as patterns, greeble objects, or gothic curves. Students express a particular design element through the visualization of emotions like isolation, excitement, or awe.

The first assignments encourage students to use only the most common Houdini nodes to create models and render still frames. Over the course exercises build in complexity to include shape language, procedural materials and tools, and motion. The final project culminates in a multi shot-music visualizer that incorporates 


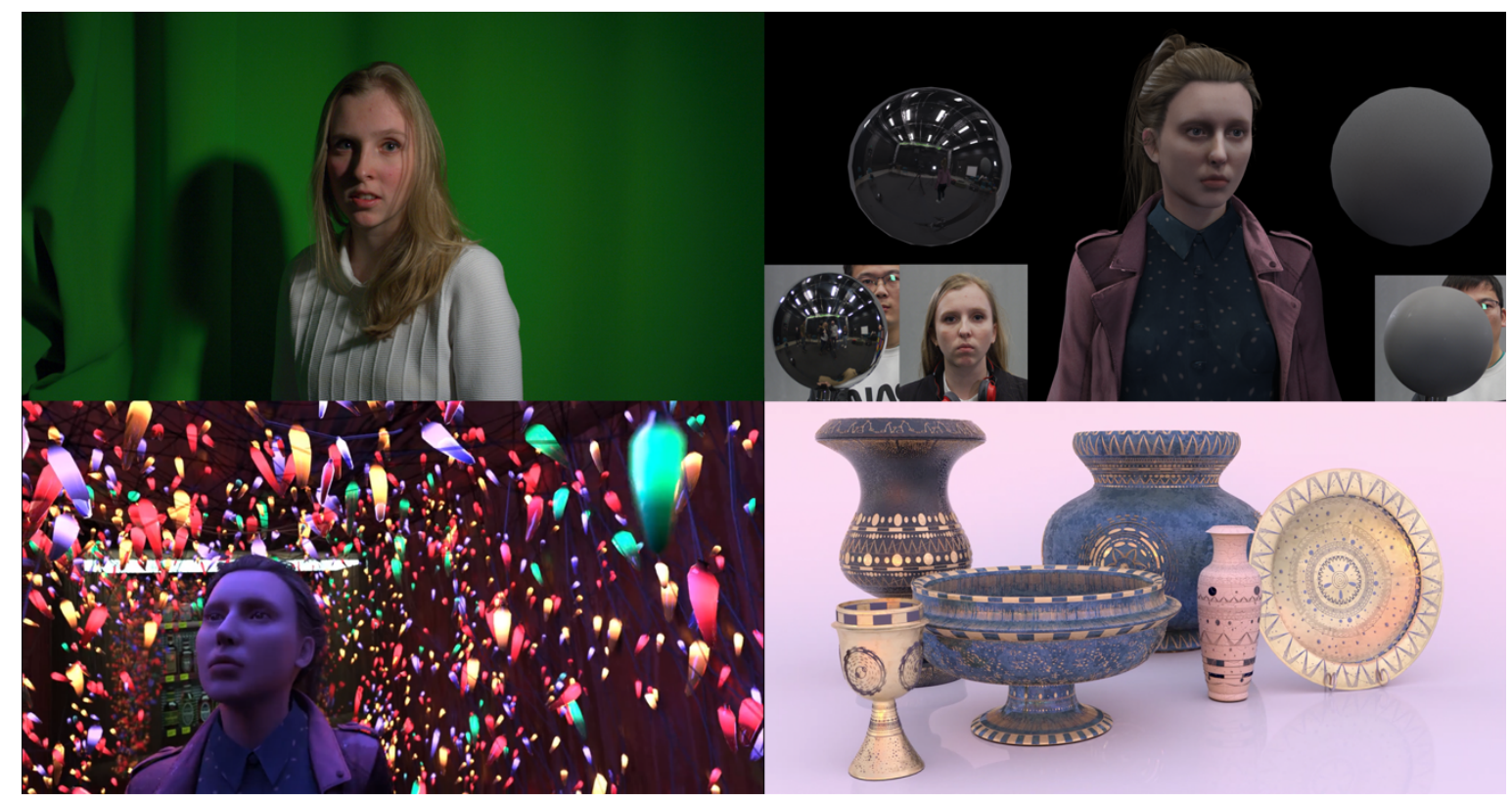

Figure 1: Lucy Jaegers, Brock Trewavas clockwise from top left: Rembrandt self-portrait, digital human, design intent expressed through procedural shape language in Houdini, cinematic tableau in Houdini. 2020.

complex design language with emotion and narrative to produce an animated music video.

\section{CENTERING STORY AND PORTRAITURE IN LIGHTING}

In Lighting and Rendering we begin the course with a discussion about Renaissance portraiture and the drive to represent both the human face and the artist's place in the world. Here a discussion of beauty, critical aesthetics, and realism informs contemporary practices of beauty lighting for cinema. Next, we pivot to the subjectivity of technical artists telling our own stories in Aotearoa New Zealand. We look at traditions of realism in colonial portraiture in New Zealand and contemporary practices in both painting and liveaction cinematography. It is necessary to address these discussions through the lens of digital cinematography so we can ask ourselves: how can we understand this history in order to both interpret and subvert it?

Concurrent with this discourse, students construct their own avatars. In earlier offerings of this course, we purchased ready-made character assets from online marketplaces. These assets produced outcomes that were proficient, but unsurprisingly, generic. When students construct digital humans in their own likeness, a level of care and narrative emerges that is both engaging and uniquely embodied by their own lived experiences. These characters form the basis from which we then explore technical aspects of lighting such as physically based materials, skin and hair shading, composition, camera movement, and render engines. These avatars function as a metric by which we "measure" affordances, differences, and realism across physical, offline, and real time lighting techniques.

\section{CONCLUSION}

Through an iterative process of ideation, pitching and visual development, students finish the program by designing and executing collaborative team-based Capstone films, an undertaking of significantly larger scope and complexity than their prior coursework. The miniature narratives and emotional arcs that are explored in small scale assignments earlier in the program function as a tool kit of procedural systems. In the Capstone this toolkit enables students to make rapid progress and author complex content to meet their vision. The Capstone projects are invariably both highly personal and technically accomplished works, embodying our core philosophy of graduating students who are both strong conceptual thinkers and technically adroit.

Over the five years in which these courses have been offered, we have found that when we ask students to go deeper into their own subjectivity in terms of story and emotion, we achieve better technical results. Future iterations of these courses will ideally lead to more immersive and interactive outputs in our Capstone practicum.

\section{ACKNOWLEDGMENTS}

The authors wish to thank Lecturer in FX \& Simulation, Sunny Teich, and the students of the Master of Design Technology Program at Victoria University of Wellington for their willingness to experiment and share their stories.

\section{APPENDIX}

https://vimeo.com/vuwmdt 